\title{
Frequency of Bubble Formation from a Multi-Hole Nozzle Attached to a Top Lance
}

\author{
Hirofumi Ooyabu ${ }^{1}$, Akira Hiratsuka ${ }^{2}$, Ryoji Tsujino ${ }^{3}$ and Manabu Iguchi ${ }^{1}$ \\ ${ }^{1}$ Graduate School of Engineering, Hokkaido University, Sapporo 060-8628, Japan \\ ${ }^{2}$ Faculty of Engineering, Osaka Sangyo University, Daito 574-8530, Japan \\ ${ }^{3}$ Faculty of Engineering, Setsunan University, Neyagawa 572-8508, Japan
}

Water model experiments have been carried out to understand the bubble formation from a multi-hole nozzle attached to an immersion top lance in the pretreatment process for sulfur. The number of holes is varied from one to four. Although desulfurization agents such as CaO particles are injected into the reactor together with carrier gas in the real process, only gas is injected, in this study, into a water bath through the holes in the horizontal direction. Three types of bubble formation patterns are observed depending on the gas flow rate: synchronized, partlysynchronized, and non-synchronized bubble formation patterns. The frequency of bubble formation at each nozzle is measured with a highspeed camera. An empirical equation is proposed for the frequency of bubble formation as a function of the number of holes, inner diameter of hole, and the physical properties of fluids. [doi:10.2320/matertrans.M2009091]

(Received March 12, 2009; Accepted April 27, 2009; Published June 25, 2009)

Keywords: water model, bubble, multi-hole nozzle, powder injection, top lance

\section{Introduction}

Various types of gas injection systems are used in the current metals refining processes: bottom gas injection, lateral gas injection, and top lance gas injection. In these processes information on the frequency of bubble formation is of essential importance because the number of bubbles generated in the reactor in one second is closely associated with the circulation velocity of molten metal due to the gaslift pump effect, the metallurgical reaction efficiency, and the removal of non-metallic inclusions. ${ }^{1-7)}$

Many efforts have been devoted to understand the frequency of bubble formation. Unfortunately, most of them are concerned with the frequency of bubble formation from a single-hole nozzle. ${ }^{1-7)}$ Data on the frequency of bubble formation from a multi-hole nozzle are very limited except for those obtained in a previous paper of the present authors. ${ }^{8)}$ Accordingly, particular attention is given in this study on the bubble formation patterns from a multi-hole nozzle in top lance gas injection. This information is useful for enhancing the efficiency of the metals refining processes.

As described in the previous paper ${ }^{8)}$ in detail, dispersion of fine particles into the molten metal bath is greatly responsible for the efficiency of the steel refining processes such as the desulfurization process. ${ }^{1-3)}$ The particles are commonly injected into the bath with carrier gas. In a strict sense, the penetration depth of particles in the reactor is affected by the interaction between the particle and the carrier gas. The penetration depth is mainly governed by the behavior of gas issuing out of the hole (or holes) settled on the side wall of the nozzle. Accordingly, as a first step of this research series, only gas was injected into a water bath. ${ }^{8)}$ The number of holes was kept two. The number of bubbles generated from the two-hole nozzle was much greater than that from a one-hole nozzle at any gas flow rate. This result means that the total interfacial area between molten iron and carrier gas is highly increased by increasing the number of holes. As a result, the metallurgical reaction between the particle and sulfur contained in the molten iron also is expected to be enhanced.

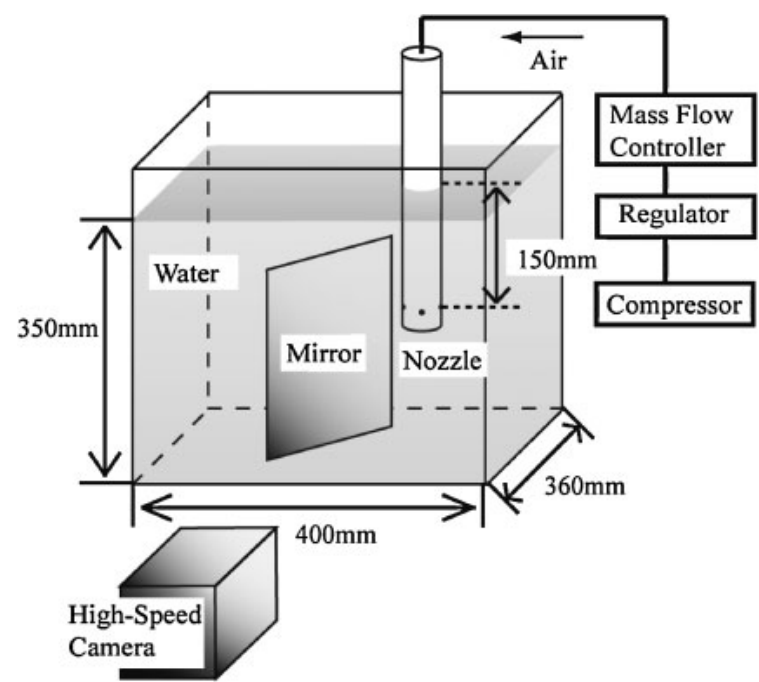

Fig. 1 Schematic of experimental apparatus.

Considering these circumstances, the number of holes was increased in this study up to four. The behavior of bubbles generated at each hole was observed with a high-speed camera and the bubble formation pattern was classified. An empirical equation for the frequency of bubble formation was proposed as a function of the operation parameters and the physical properties of fluids.

\section{Experimental Apparatus and Procedure}

Figure 1 shows a schematic diagram of the experimental apparatus. Although we are planning to attach a nozzle with multi-holes to the top lance in the real desulfurization process, the top lance is not shown in Fig. 1 in order to avoid crowding in the figure. The test vessel had a cross-section of $360 \mathrm{~mm} \times 400 \mathrm{~mm}$ and a height of $440 \mathrm{~mm}$. Air was supplied with a compressor and injected into a water bath through an immersion lance. The flow rate of air, $Q_{\mathrm{g}}$, was controlled with a mass flow controller. A nozzle having four holes on its 

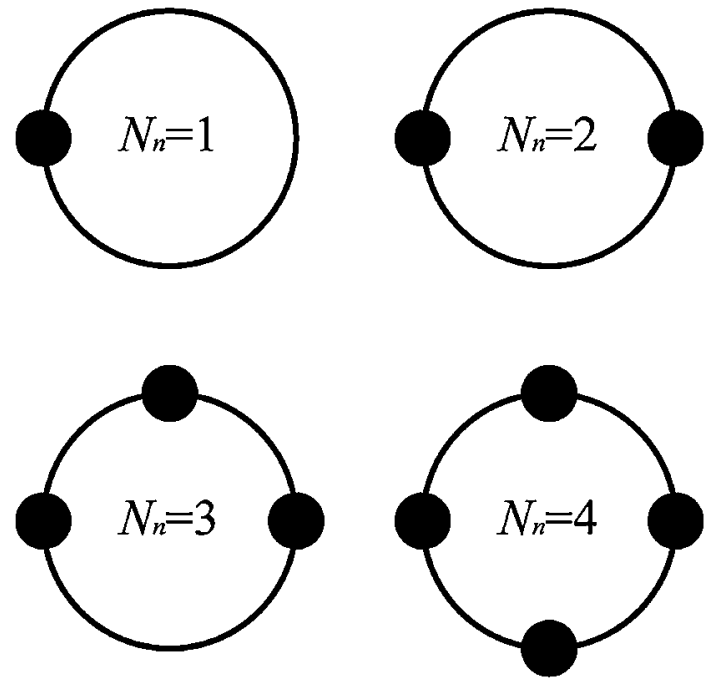

Fig. 2 Hole position.

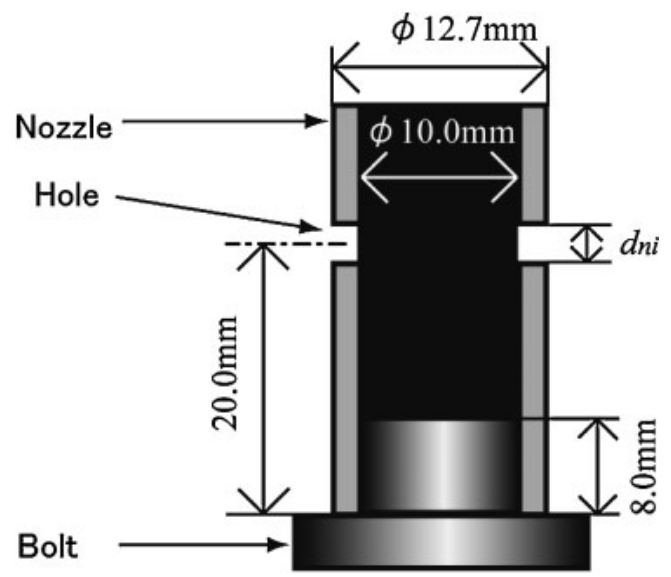

Fig. 3 Details of nozzle.

side wall was attached to the lance. They are placed on the same perimeter at equal intervals of $90^{\circ}$, as shown in Fig. 2. The inner diameters of the four holes are the same. The nozzle was made of brass pipe and its bottom was closed with a bolt. The brass pipe was wetted by water. The inner diameter, $D_{\mathrm{i}}$, of the nozzle and the inner diameter of the hole, $d_{\text {ni }}$, are shown in Fig. 3. The outer diameter of the nozzle was kept at $12.7 \mathrm{~mm}$.

The behavior of bubbles successively generated at each exit of the holes was observed with a high-speed camera at $630 \mathrm{fps}$. A mirror was placed in the bath to observe the bubble formation from the rear hole, as shown in Fig. 4 in detail. The gas flow rate, $Q_{\mathrm{g}}$, was varied from $5 \mathrm{~cm}^{3} / \mathrm{s}$ to $90 \mathrm{~cm}^{3} / \mathrm{s}$. Measurements of the frequency of bubble formation were repeated three times under every experimental condition.

\section{Experimental Results and Discussion}

\subsection{Classification of bubble formation pattern}

In the previous investigation ${ }^{8)}$ two types of bubble formation patterns were observed for a two-hole nozzle: synchronized and non-synchronized bubble formation patterns. In the former pattern bubbles were simultaneously

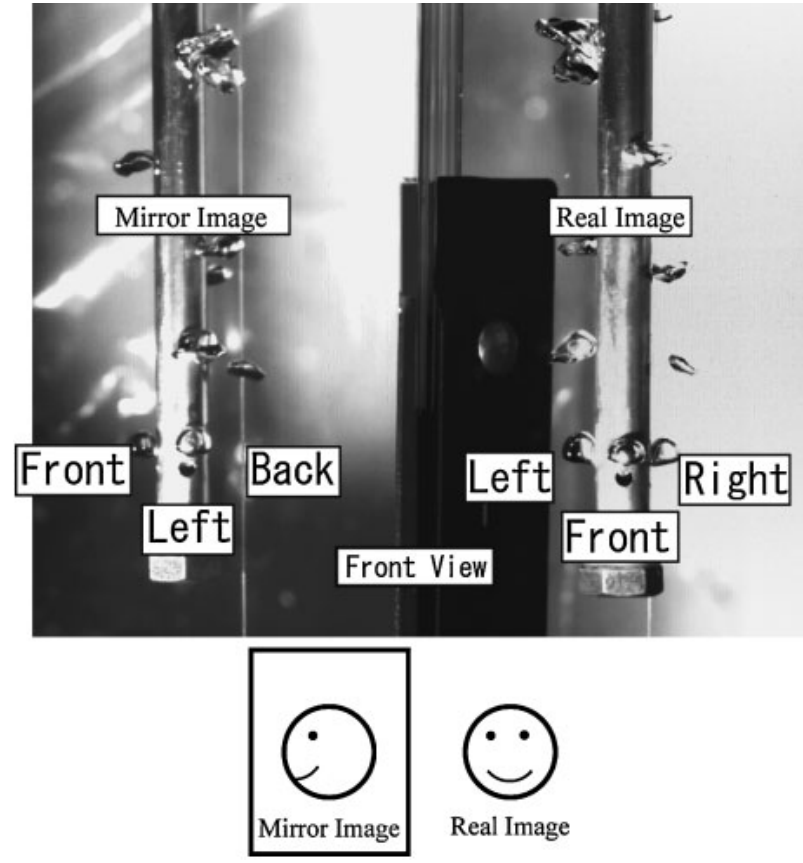

Fig. 4 Real and mirror images.

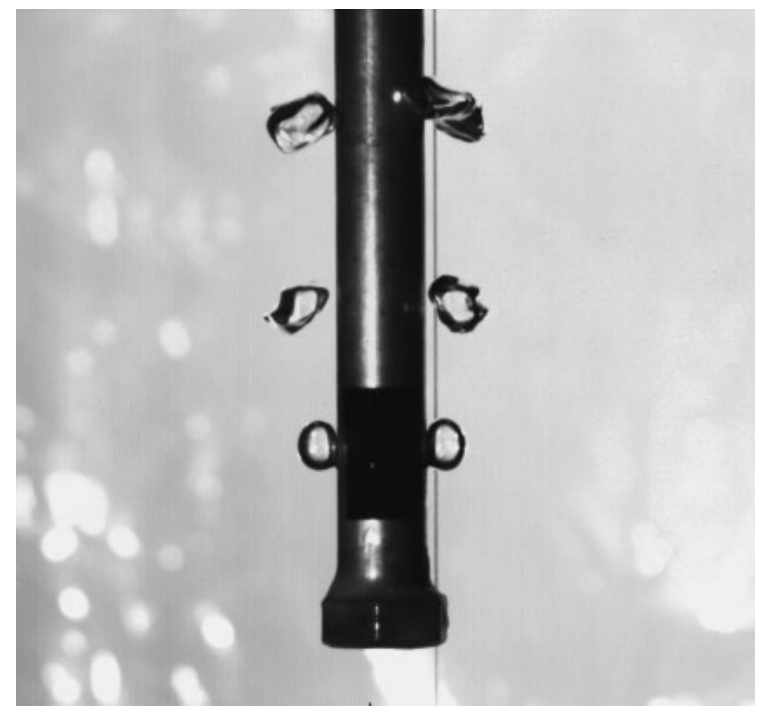

Fig. 5 Synchronized bubble formation $\left(N_{\mathrm{n}}=2, d_{\mathrm{ni}}=2.0 \mathrm{~mm}, Q_{\mathrm{g}}=\right.$ $\left.10 \mathrm{~cm}^{3} / \mathrm{s}\right)$.

generated at the two holes and they rose at nearly the same rise velocity, as shown in Fig. 5. On the other hand, in the latter pattern bubbles were generated alternatively at the two holes.

A synchronization ratio, $R_{\text {syn }}$, was introduced to describe the transition of bubble formation pattern.

$$
R_{\text {syn }}=100 n_{\mathrm{s}} / n_{\mathrm{t}}
$$

where $n_{\mathrm{s}}$ is the number of bubbles generated simultaneously at two holes and $n_{\mathrm{t}}$ is the total number of bubbles in a predetermined time. When bubbles are simultaneously generated, $R_{\text {syn }}$ is defined to have a value of 100 . On the other hand, when bubbles are alternately generated all the time, $R_{\text {syn }}$ is defined to have a value of zero. It should be 


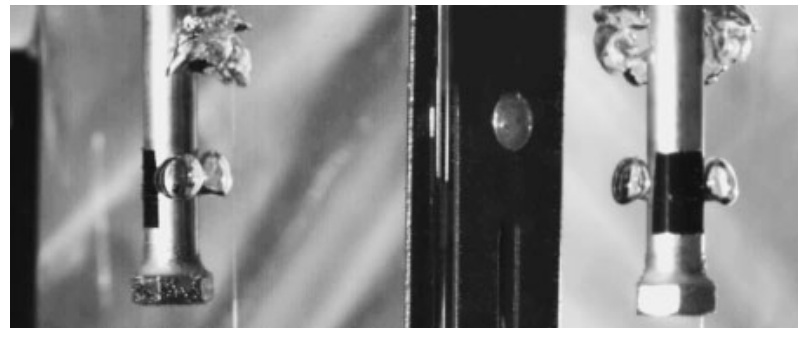

Fig. 6 Synchronized bubble formation $\left(N_{\mathrm{n}}=3, d_{\mathrm{ni}}=3.0 \mathrm{~mm}, Q_{\mathrm{g}}=\right.$ $\left.40 \mathrm{~cm}^{3} / \mathrm{s}\right)$.

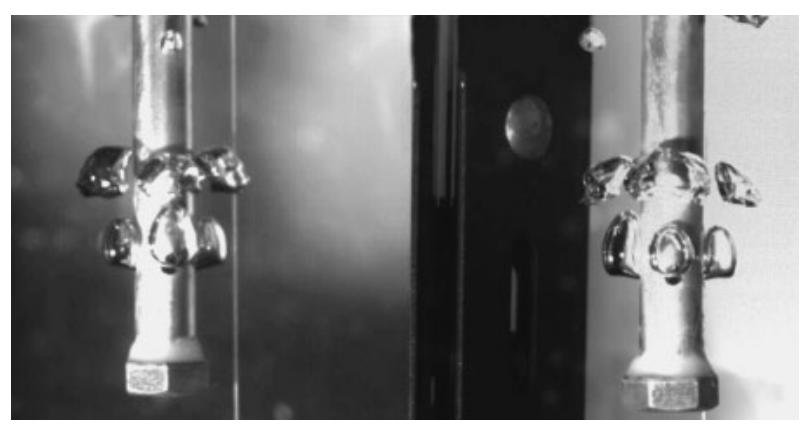

Fig. 7 Synchronized bubble formation $\left(N_{\mathrm{n}}=4, d_{\mathrm{ni}}=4.0 \mathrm{~mm}, Q_{\mathrm{g}}=\right.$ $\left.40 \mathrm{~cm}^{3} / \mathrm{s}\right)$.

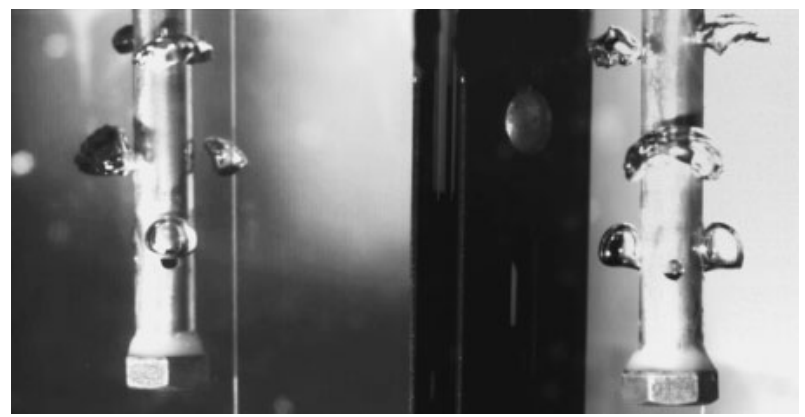

Fig. 8 Partly-synchronized bubble formation $\left(N_{\mathrm{n}}=4, d_{\mathrm{ni}}=4.0 \mathrm{~mm}\right.$, $\left.Q_{\mathrm{g}}=20 \mathrm{~cm}^{3} / \mathrm{s}\right)$.

noted that $R_{\text {syn }}$ was used in this study in place of the previously used symbol, $n$, in order to avoid confusion with the index of an empirical equation for the frequency of bubble formation. ${ }^{8)}$

The same synchronized bubble formation pattern was observed in this study for a three-hole nozzle (see Fig. 6) and a four-hole nozzle (see Fig. 7). Concerning the four-hole nozzle, 4 are added to $n_{\mathrm{s}}$ only when bubbles are simultaneously generated from the four holes, otherwise $n_{\mathrm{s}}$ is not increased.

In the case of four-hole nozzle, bubbles were generated simultaneously from two holes placed on the opposite sides, as shown in Fig. 8. This type was observed at the first time and named the partly-synchronized bubble formation pattern. It should be noted that $R_{\text {syn }}$ is zero in this case.

Figures 9 through 12 show the synchronization ratio, $R_{\mathrm{syn}}$, for inner hole diameters of $1 \mathrm{~mm}, 2 \mathrm{~mm}, 3 \mathrm{~mm}$, and $4 \mathrm{~mm}$, respectively. In Figs. 11 and $12 R_{\text {syn }}$ increased with an increase in the gas flow rate, $Q_{\mathrm{g}}$, reached 100 and then

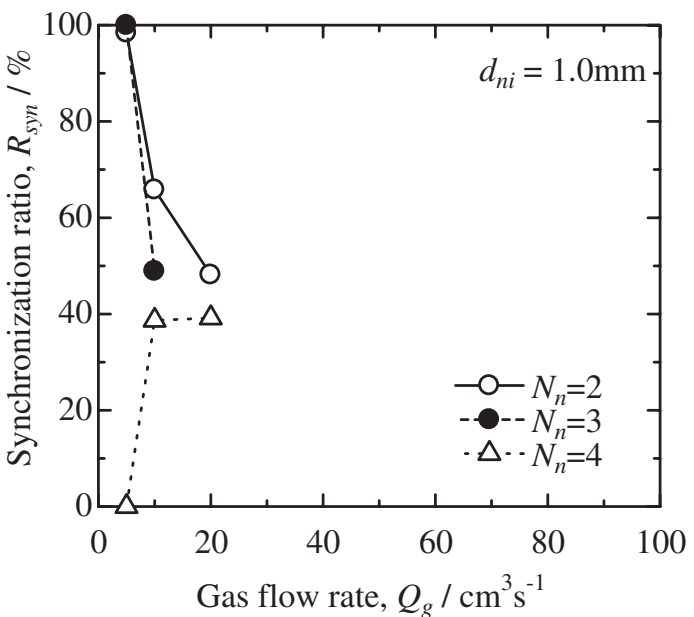

Fig. 9 Synchronized bubbling ratio $\left(d_{\mathrm{ni}}=1.0 \mathrm{~mm}\right)$.

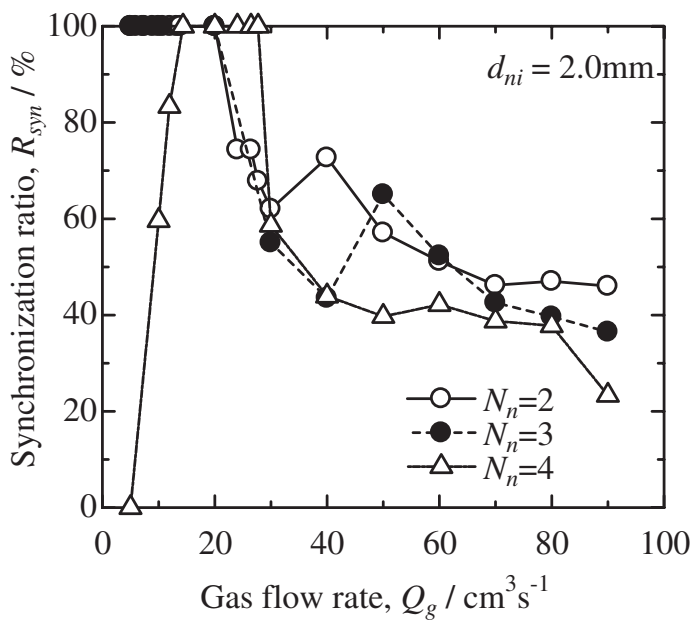

Fig. 10 Synchronized bubbling ratio $\left(d_{\mathrm{ni}}=2.0 \mathrm{~mm}\right)$.

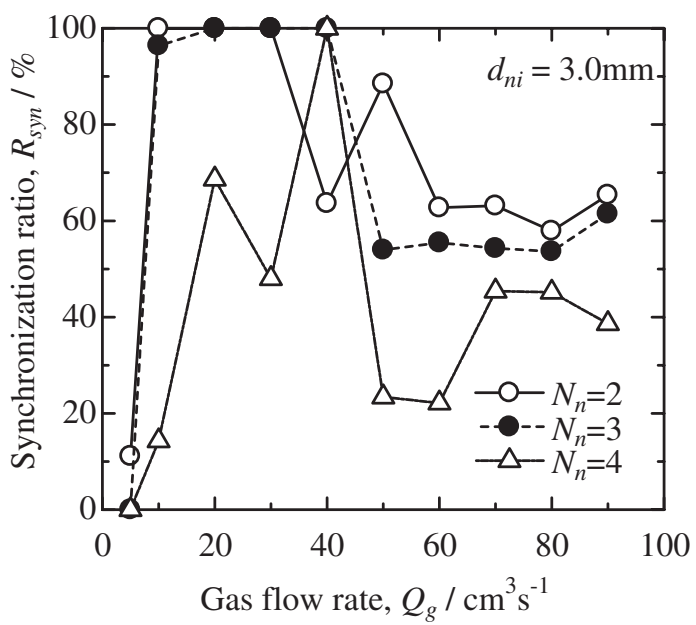

Fig. 11 Synchronized bubbling ratio $\left(d_{\mathrm{ni}}=3.0 \mathrm{~mm}\right)$.

decreased. However, $R_{\text {syn }}$ never became zero after showing 100 in the higher gas flow rate regime. The measured values of $R_{\text {syn }}$ for $N_{\mathrm{n}}=2$ and 3 in Figs. 9 and 10 also increased with $Q_{\mathrm{g}}$ in the gas flow rate regime below $5 \mathrm{~cm}^{3} / \mathrm{s}$. The data 


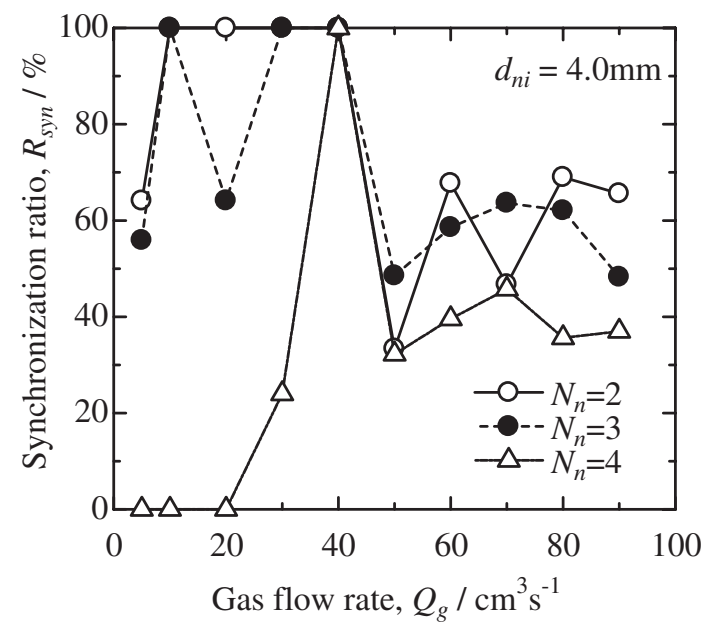

Fig. 12 Synchronized bubbling ratio $\left(d_{\mathrm{ni}}=4.0 \mathrm{~mm}\right)$.

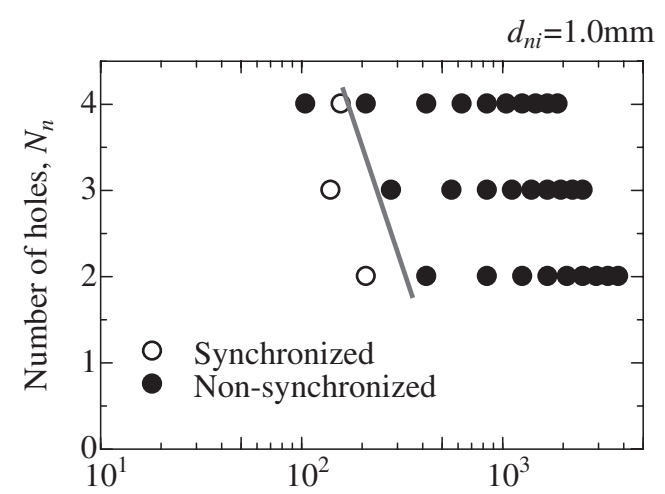

Reynolds number based on the hole diameter, $R e_{n}$

Fig. 13 Bubble formation pattern map $\left(d_{\mathrm{ni}}=1.0 \mathrm{~mm}\right)$.

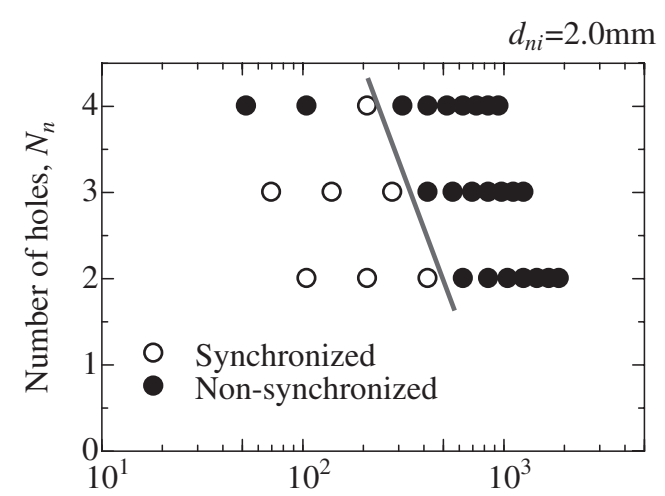

Reynolds number based on the hole diameter, $R e_{n}$

Fig. 14 Bubble formation pattern map $\left(d_{\mathrm{ni}}=2.0 \mathrm{~mm}\right)$.

however were not plotted in these figures due to poor accuracy of the mass flow controller in this gas flow rate regime.

\subsection{Bubble formation pattern map}

Figures 13 through 16 show the bubble formation pattern map for multi-hole nozzles of $d_{\mathrm{ni}}$ of $1 \mathrm{~mm}, 2 \mathrm{~mm}, 3 \mathrm{~mm}$, and $4 \mathrm{~mm}$, respectively as a function of the number of holes, $N_{\mathrm{n}}$, and the following Reynolds number, $\mathrm{Re}_{\mathrm{n}}$.

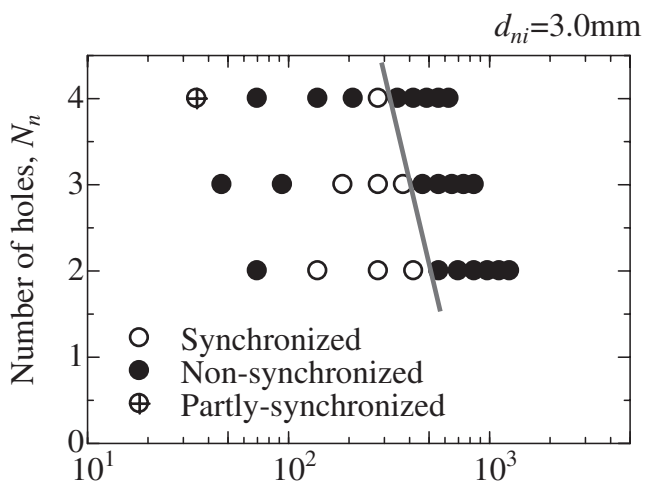

Reynolds number based on the hole diameter, $R e_{n}$

Fig. 15 Bubble formation pattern map $\left(d_{\mathrm{ni}}=3.0 \mathrm{~mm}\right)$.

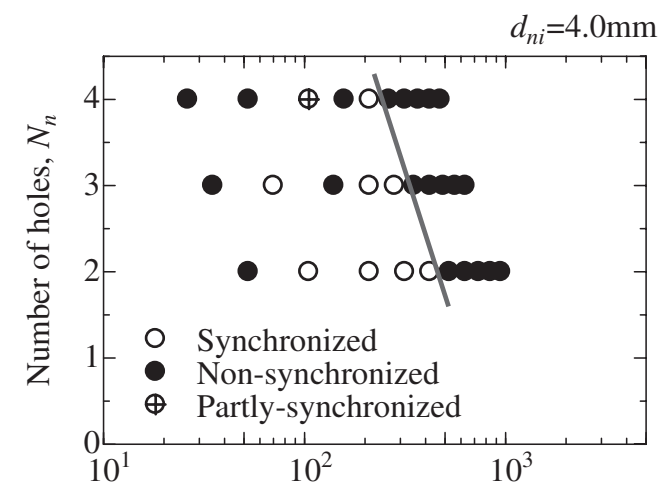

Reynolds number based on the hole diameter, $R e_{n}$

Fig. 16 Bubble formation pattern map $\left(d_{\mathrm{ni}}=4.0 \mathrm{~mm}\right)$.

$$
\operatorname{Re}_{\mathrm{n}}=4 Q_{\mathrm{g}} /\left(\pi v_{\mathrm{g}} d_{\mathrm{ni}} N_{\mathrm{n}}\right)
$$

where $v_{\mathrm{g}}$ is the kinematic viscosity of gas issuing out of the hole. Open circles denote the synchronized bubble formation pattern in which $R_{\mathrm{syn}}$ is $100 \%$. Precise measurement of the frequency of bubble formation, $f_{\mathrm{B}}$, is necessary to obtain $R_{\text {syn }}$. It became difficult to count the number of bubbles generated from four nozzles of $d_{\mathrm{ni}}=1 \mathrm{~mm}$ for $Q_{\mathrm{g}}>20$ $\mathrm{cm}^{3} / \mathrm{s}$ because of overlapping of the bubbles. Fortunately, judgment of bubble formation patterns was possible even if $Q_{\mathrm{g}}$ was raised above $20 \mathrm{~cm}^{3} / \mathrm{s}$. This is the reason why the number of data shown in Fig. 13 is much greater than that in Fig. 9. It seems that the bubble formation pattern is closely associated with the hydrodynamic drag at each hole of the nozzle, as shown in the following section. The hydrodynamic drag varies depending on the Reynolds number of flow issuing out of each hole, $\operatorname{Re}_{\mathrm{n}}$. This is the main reason why $\mathrm{Re}_{\mathrm{n}}$ was chosen here to correlate the bubble formation pattern. The boundary between the synchronized and nonsynchronized flow patterns in higher Reynolds number regime can be satisfactorily correlated by this arrangement method, as indicated by a thick solid line in each figure. Unfortunately, it is difficult at present to identify the occurrence condition of the partly-synchronized bubble formation pattern for a four-hole nozzle due to lack of data points. 


\subsection{Mechanism of synchronized bubble formation}

The pressure drop at one of the holes, $\Delta p_{\mathrm{i}}$, is expressed by

$$
\begin{aligned}
\Delta p_{\mathrm{i}} & =\zeta_{\mathrm{i}} \rho_{\mathrm{g}} v_{\mathrm{m}, \mathrm{i}}{ }^{2} / 2 \quad(\mathrm{i}=1,2,3,4) \\
v_{\mathrm{m}, \mathrm{i}} & =Q_{\mathrm{g}, \mathrm{i}} / A_{\mathrm{n}, \mathrm{i}} \\
A_{\mathrm{n}, \mathrm{i}} & =\pi d_{\mathrm{ni}, \mathrm{i}}{ }^{2} / 4
\end{aligned}
$$

where $\zeta_{\mathrm{i}}$ is the loss coefficient, $\rho_{\mathrm{g}}$ is the density of gas, $v_{\mathrm{m}, \mathrm{i}}$ is the cross-sectional mean velocity, $Q_{\mathrm{g}, \mathrm{i}}$ is the gas flow rate, $A_{\mathrm{i}}$ is the cross-sectional area of the hole.

The power loss at that hole is given by

$$
P_{\mathrm{w}, \mathrm{i}}=\Delta p_{\mathrm{i}} Q_{\mathrm{g}, \mathrm{i}}
$$

The total power loss, $P_{\mathrm{w}}$, therefore is expressed by

$$
\begin{aligned}
P_{\mathrm{w}} & =\Sigma \Delta p_{\mathrm{i}} Q_{\mathrm{g}, \mathrm{i}} \\
& =\left(\pi \rho_{\mathrm{g}} / 8\right) \Sigma \zeta_{\mathrm{i}} d_{\mathrm{ni}, \mathrm{i}}{ }^{2} v_{\mathrm{m}, \mathrm{i}}{ }^{3}
\end{aligned}
$$

As the holes have the same inner diameter

$$
d_{\mathrm{ni}, \mathrm{i}}=d_{\mathrm{ni}}
$$

the loss coefficient, $\zeta_{\mathrm{i}}$, is regarded as a constant.

$$
\zeta_{\mathrm{i}}=\zeta
$$

Accordingly, eq. (7) reduces to

$$
P_{\mathrm{w}}=\left(\pi \rho_{\mathrm{g}} \zeta d_{\mathrm{ni}}^{2} / 8\right) \Sigma v_{\mathrm{m}, \mathrm{i}}^{3}
$$

The following relationship holds under the same condition due to mass balance.

$$
\begin{aligned}
& Q_{\mathrm{g}}=\Sigma A_{\mathrm{n}, \mathrm{i}} v_{\mathrm{m}, \mathrm{i}}=A_{\mathrm{n}} \Sigma v_{\mathrm{m}, \mathrm{i}} \\
& A_{\mathrm{n}}=A_{\mathrm{n}, \mathrm{i}}
\end{aligned}
$$

\subsubsection{Condition of synchronized and partly-synchron-} ized bubble formation for multi-hole nozzle

The minimum power loss condition can be obtained by solving eq. (13) and eq. (14) for conditional extreme problem in the example of four-hole nozzle.

$$
\begin{aligned}
& F\left(v_{\mathrm{m}, 1}, v_{\mathrm{m}, 2}, v_{\mathrm{m}, 3}, v_{\mathrm{m}, 4}, \lambda\right) \\
& =P_{\mathrm{w}}\left(v_{\mathrm{m}, 1}{ }^{3}, v_{\mathrm{m}, 2}{ }^{3}, v_{\left.\mathrm{m}, 3^{3}, v_{\mathrm{m}, 4}{ }^{3}\right)}\right. \\
& \quad-\lambda\left(v_{\mathrm{m}, 1}+v_{\mathrm{m}, 2}+v_{\mathrm{m}, 3}+v_{\mathrm{m}, 4}-\mathrm{C}\right) \\
& \Sigma v_{\mathrm{m}, \mathrm{i}}=Q_{\mathrm{g}} / A_{\mathrm{n}}=\text { const. }=\mathrm{C}
\end{aligned}
$$

where $F$ and $P_{\mathrm{w}}$ are the functions and $\lambda$ is Lagrange multiplier (= const.). By solving eq. (13) and eq. (14), extreme condition is achieved in the following manner.

$$
\begin{aligned}
& v_{\mathrm{m}, 1}^{2}=v_{\mathrm{m}, 2}{ }^{2}=v_{\mathrm{m}, 3}{ }^{2}=v_{\mathrm{m}, 4}{ }^{2} \\
& \text { namely }\left|v_{\mathrm{m}, 1}\right|=\left|v_{\mathrm{m}, 2}\right|=\left|v_{\mathrm{m}, 3}\right|=\left|v_{\mathrm{m}, 4}\right|
\end{aligned}
$$

Considering eq. (14), the solutions of eq. (16) are

Answer 1: every $v_{\mathrm{m}, \mathrm{i}}$ is $1 / 4 \mathrm{C}$

Answer 2: two of the $v_{\mathrm{m}, \mathrm{i}}$ are $1 / 2 \mathrm{C}$

$$
\text { and remaining two are } \pm 1 / 2 \mathrm{C}
$$

As for answer 1, synchronized bubble formation occurs in this condition. As for answer 2, partly-synchronized bubble formation pattern, as mentioned earlier, appears in this condition. Actually, in partly-synchronized bubble formation pattern, bubbles which almost become to generate in the outlet of the some remaining holes are observed to be sucked and disappear into the nozzle.
Next, in the same manner, concerning three-hole nozzle,

$$
\begin{aligned}
& v_{\mathrm{m}, 1}^{2}=v_{\mathrm{m}, 2}{ }^{2}=v_{\mathrm{m}, 3}{ }^{2} \\
& \text { namely }\left|v_{\mathrm{m}, 1}\right|=\left|v_{\mathrm{m}, 2}\right|=\left|v_{\mathrm{m}, 3}\right|
\end{aligned}
$$

is obtained. In this case, only one answer 1 : every $v_{\mathrm{m}, \mathrm{i}}=$ $1 / 3 \mathrm{C}$, can be solved, because answer 2 , any $v_{\mathrm{m}, \mathrm{i}}$ have equal absolute value with different sign of plus or minus, is impossible.

In the case of three-hole nozzle, in this study, partlysynchronized bubble formation pattern can't be actually observed in comparison to four-hole nozzle.

Concerning two-hole nozzle,

$$
\begin{aligned}
& v_{\mathrm{m}, 1}{ }^{2}=v_{\mathrm{m}, 2}{ }^{2} \\
& \text { namely }\left|v_{\mathrm{m}, 1}\right|=\left|v_{\mathrm{m}, 2}\right|
\end{aligned}
$$

is obtained. In this case, two answers 1 and 2 can be solved. Answer 1: every $v_{\mathrm{m}, \mathrm{i}}=1 / 2 \mathrm{C}$ and answer 2: $v_{\mathrm{m}, 1}=-v_{\mathrm{m}, 2}$ with equal absolute value are theoretically possible. However, in this study, such a case of answer 2 can't be observed because of unbalance of the pressure in the nozzle.

Accordingly, synchronized bubble formation occurs under the following condition for every multi-hole nozzle.

$$
\begin{gathered}
v_{\mathrm{m}, 1}=v_{\mathrm{m}, 2}=\left(Q_{\mathrm{g}} / A_{\mathrm{n}}\right) / 2 \quad \\
v_{\mathrm{m}, 1}=v_{\mathrm{m}, 2}=v_{\mathrm{m}, 3}=\left(Q_{\mathrm{g}} / A_{\mathrm{n}}\right) / 3 \\
\quad(\text { three-hole nozzle }) \\
v_{\mathrm{m}, 1}=v_{\mathrm{m}, 2}=v_{\mathrm{m}, 3}=v_{\mathrm{m}, 4}=\left(Q_{\mathrm{g}} / A_{\mathrm{n}}\right) / 4 \\
\quad(\text { four-hole nozzle })
\end{gathered}
$$

On the contrary, partly synchronized bubble formation occurs only in the next condition of four-hole nozzle.

Two of the $v_{\mathrm{m}, \mathrm{i}}$ are $1 / 2 \mathrm{C}$ and the remaining two are $\pm 1 / 2 \mathrm{C}$.

When the gas flow rate, $Q_{\mathrm{g}}$, is relatively low, it is easy for the fluid in the nozzle to adjust the flow rate through each hole to the same value. As $Q_{\mathrm{g}}$ becomes high, such adjustment becomes impossible and the so-called overshooting phenomenon takes place as mentioned in the previous paper. ${ }^{8)}$ This is the reason why bubbles are generated in the non-synchronized pattern in a high gas flow rate regime. On the other hand, bubbles were preferably generated from any one of multi-holes in a very low gas flow rate regime $\left(R_{\text {syn }}=0\right)$. Consequently, the minimum power loss condition is realized in a limited gas flow rate regime. Detailed discussion on this condition must be left for a future study.

\subsection{Derivation of an empirical equation for the fre- quency of bubble formation at multi-hole nozzle}

3.4.1 Previous empirical equation for the frequency of bubble formation at a single-hole nozzle

One of the authors proposed previously the following empirical equation ${ }^{4,5,8)}$ for a single-hole nozzle under the constant flow condition. ${ }^{6,7)}$

$$
f_{\mathrm{B}}=1.06 k\left(\rho_{\mathrm{L}} \mathrm{g}^{3} / \sigma\right)^{1 / 4}\left(\rho_{\mathrm{g}} / \rho_{\mathrm{L}}\right)^{1 / 5}\left[\left(Q_{\mathrm{g}}{ }^{2} / \mathrm{g}\right)^{1 / 5} / d_{\mathrm{ni}}\right]^{n}
$$

where $k$ is constant, $\rho_{\mathrm{L}}$ is the density of liquid, $\mathrm{g}$ is the acceleration due to gravity, $\sigma$ is the surface tension and $\rho_{\mathrm{g}}$ is the density of gas. The coefficient, $k$, and the index, $n$, depend on the configuration of the nozzle. This equation is used for deriving an empirical equation of the frequency of bubble formation from a multi-hole nozzle. 


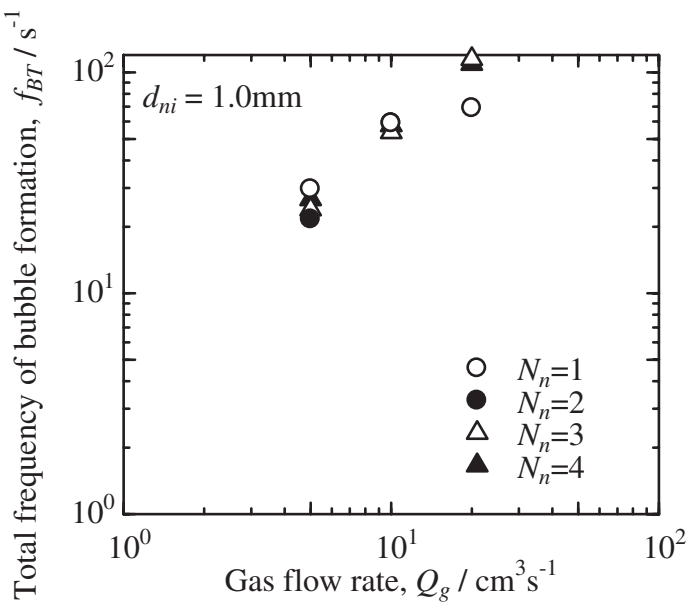

Fig. 17 Relationship between total frequency of bubble formation and gas flow rate $\left(d_{\mathrm{ni}}=1.0 \mathrm{~mm}\right)$.

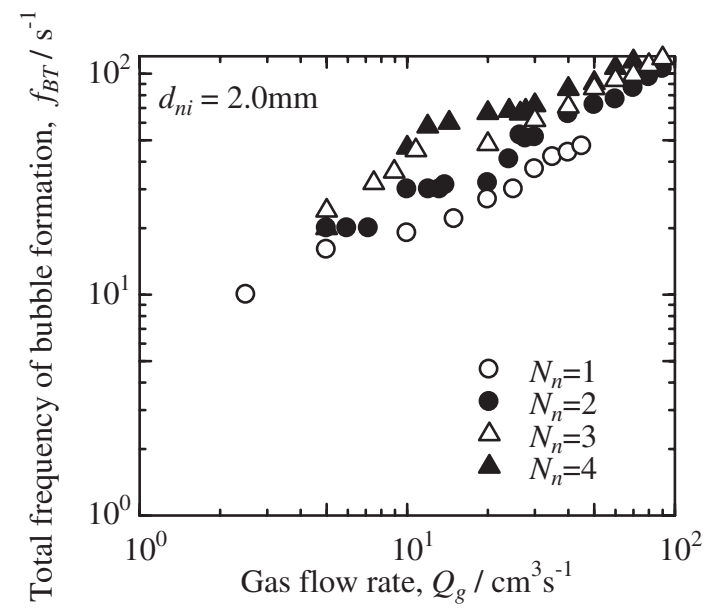

Fig. 18 Relationship between total frequency of bubble formation and gas flow rate $\left(d_{\mathrm{ni}}=2.0 \mathrm{~mm}\right)$.

\subsubsection{Experimental results of the frequency of bubble formation}

(1) Total frequency of bubble formation, $f_{\mathrm{BT}}$

Figures 17 through 20 show the measured values of the total frequency of bubble formation, $f_{\mathrm{BT}}$, for the four-hole nozzles of $d_{\mathrm{ni}}$ of $1 \mathrm{~mm}, 2 \mathrm{~mm}, 3 \mathrm{~mm}$, and $4 \mathrm{~mm}$, respectively as a function of gas flow rate, $Q_{\mathrm{g}}$, and the number of holes, $N_{\mathrm{n}}$. It should be stressed that $f_{\mathrm{BT}}$ is the number of bubbles generated from all holes of the nozzle in one second and $f_{\mathrm{B}}$ is the number of bubbles generated from each hole in one second. These figures collectively mean that the total frequency of bubble formation increases as $Q_{\mathrm{g}}$ and $N_{\mathrm{n}}$ increase. When the gas flow rate is kept constant, the interfacial area between bubbles and liquid can be increased by increasing the number of holes.

(2) Frequency of bubble formation, $f_{\mathrm{B}}$, at each hole

The frequency of bubble formation, $f_{\mathrm{B}}$, was found to be the same at every hole regardless of the bubble formation pattern. Accordingly, the total frequency of bubble formation, $f_{\mathrm{BT}}$, was divided by $N_{\mathrm{n}}$ and plotted against the gas flow rate at each hole, $Q_{\mathrm{g}} / N_{\mathrm{n}}$, in Figs. 21 through 24 . It is evident in

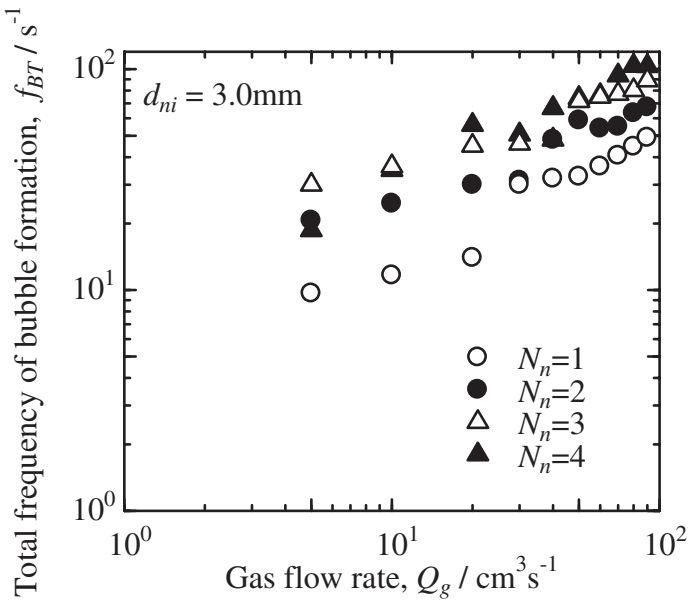

Fig. 19 Relationship between total frequency of bubble formation and gas flow rate $\left(d_{\mathrm{ni}}=3.0 \mathrm{~mm}\right)$.

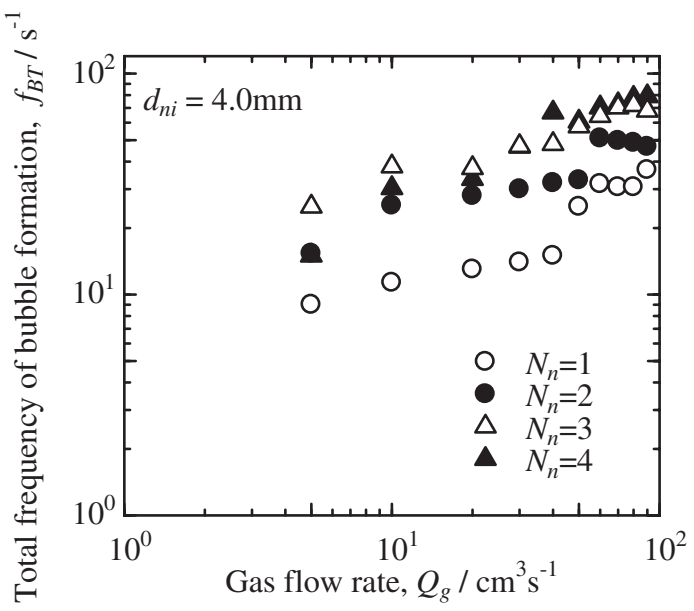

Fig. 20 Relationship between total frequency of bubble formation and gas flow rate $\left(d_{\mathrm{ni}}=4.0 \mathrm{~mm}\right)$.

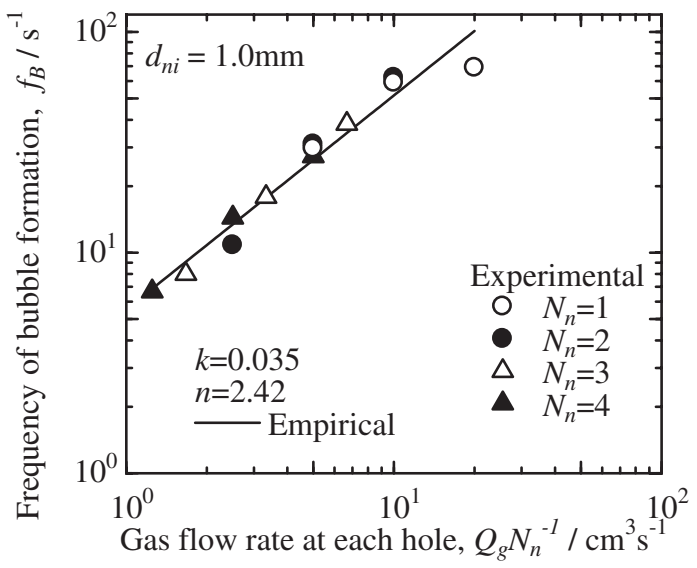

Fig. 21 Relationship between frequency of bubble formation and gas flow rate at each hole $\left(d_{\mathrm{ni}}=1.0 \mathrm{~mm}\right)$.

each figure that the measured values of $f_{\mathrm{B}}$ for the nozzles of different number of holes overlap with one another. Accordingly, the measured values of $f_{\mathrm{B}}$ were approximated by the following empirical equation. 


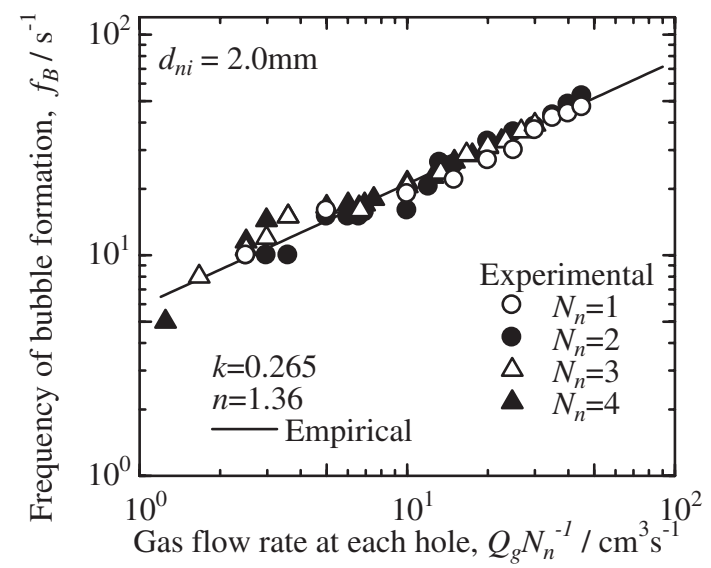

Fig. 22 Relationship between frequency of bubble formation and gas flow rate at each hole $\left(d_{\mathrm{ni}}=2.0 \mathrm{~mm}\right)$.

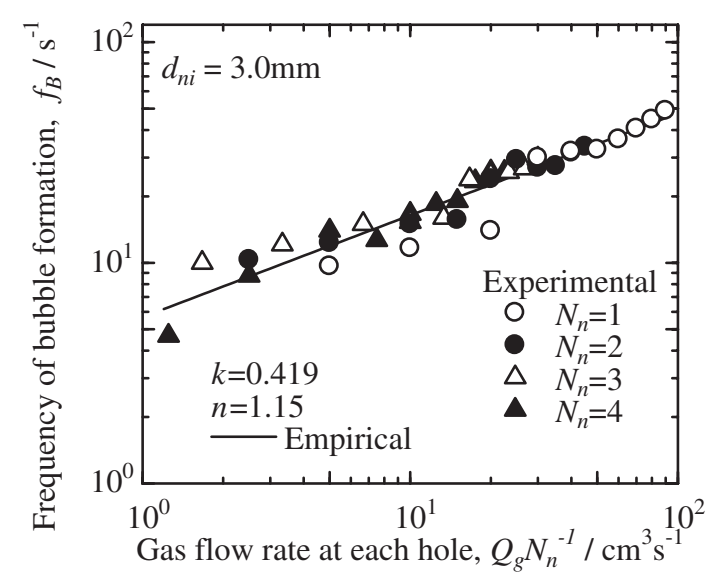

Fig. 23 Relationship between frequency of bubble formation and gas flow rate at each hole $\left(d_{\mathrm{ni}}=3.0 \mathrm{~mm}\right)$.

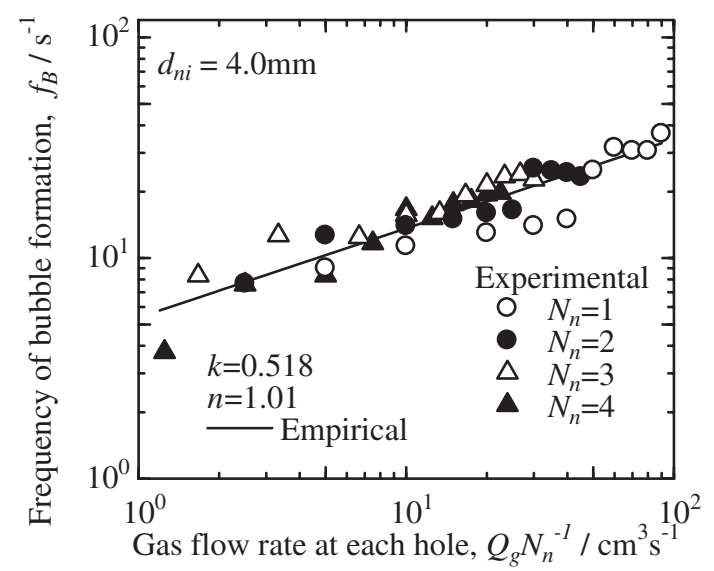

Fig. 24 Relationship between frequency of bubble formation and gas flow rate at each hole $\left(d_{\mathrm{ni}}=4.0 \mathrm{~mm}\right)$.

$$
f_{\mathrm{B}}=1.06 k\left(\rho_{\mathrm{L}} \mathrm{g}^{3} / \sigma\right)^{1 / 4}\left(\rho_{\mathrm{g}} / \rho_{\mathrm{L}}\right)^{1 / 5}\left[\left\{\left(Q_{\mathrm{g}} / N_{\mathrm{n}}\right)^{2} / \mathrm{g}\right\}^{1 / 5} / d_{\mathrm{ni}}\right]^{n}
$$

As mentioned earlier, the bubble formation pattern depends on the distance among holes in the nozzle. This

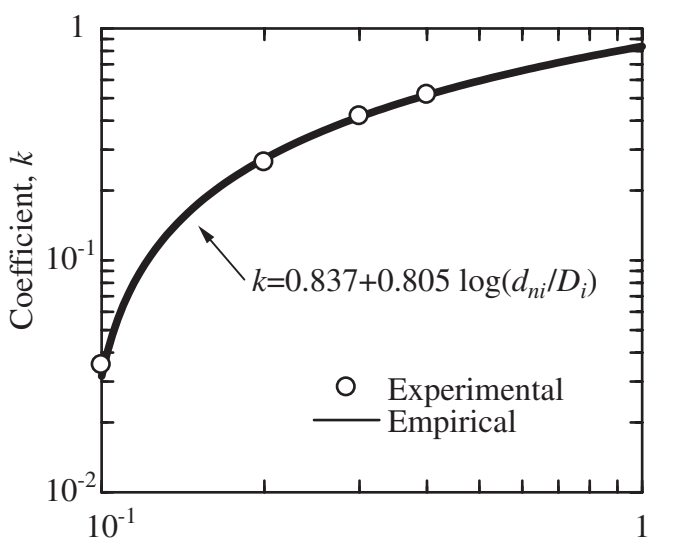

Ratio of hole diameter to nozzle diameter, $d_{n i} D_{i}^{-1}$

Fig. 25 Relationship between $k$ and $d_{\text {ni }} / D_{\mathrm{i}}$.

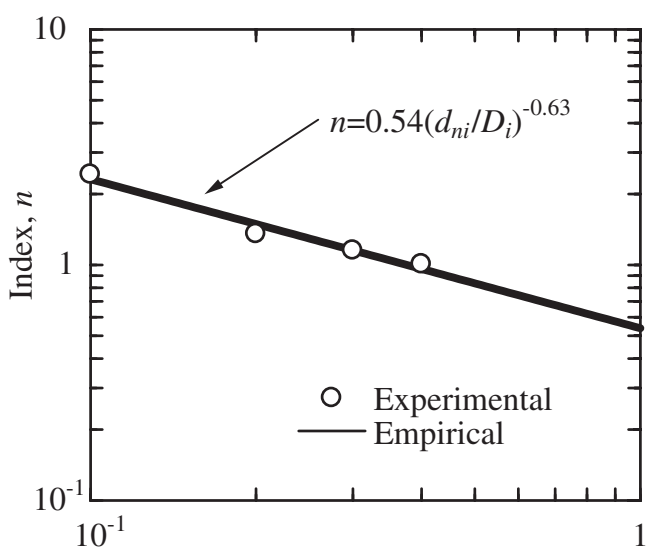

Ratio of hole diameter to nozzle diameter, $d_{n i} D_{i}^{-1}$

Fig. 26 Relationship between $n$ and $d_{\text {ni }} / D_{\mathrm{i}}$.

distance is represented by the inner diameter of the nozzle, $D_{\mathrm{i}}$. Accordingly, $d_{\mathrm{ni}} / D_{\mathrm{i}}$ was chosen to correlate the measured values of $k$ and $n$. The values of $k$ and $n$ thus determined were plotted against the dimensionless nozzle diameter, $d_{\mathrm{ni}} / D_{\mathrm{i}}$, in Figs. 25 and 26, respectively. The following equations were derived.

$$
\begin{aligned}
& k=0.837+0.805 \log \left(d_{\text {ni }} / D_{\mathrm{i}}\right) \\
& n=0.54\left(d_{\mathrm{ni}} / D_{\mathrm{i}}\right)^{-0.63}
\end{aligned}
$$

\section{Conclusions}

The behavior of bubbles successively generated from a multi-hole nozzle attached to a top lance was observed with a high-speed camera. Some holes of the same inner diameter were settled on the same periphery of the nozzle. Main findings obtained in this study can be summarized as follows:

(1) Three types of bubble formation patterns were observed: synchronized, partly-synchronized, and nonsynchronized bubble formation patterns. The flow pattern map was correlated as a function of the number of holes, $N_{\mathrm{n}}$, and the Reynolds number based on the hole diameter, $\operatorname{Re}_{\mathrm{n}}$. 
(2) The mechanism of synchronized and partly-synchronized bubble formations was predicted by solving the conditional extreme problem.

(3) The measured values of the frequency of bubble formation at the holes of a multi-hole nozzle were nearly equal to one another regardless of bubble formation patterns.

(4) The frequency of bubble formation from each nozzle, $f_{\mathrm{B}}$, was satisfactorily approximated by an empirical equation, eq. (27), proposed in this study.

\section{REFERENCES}

1) K. Mori and M. Sano: Tetsu-to-Hagane 67 (1981) 672-695.

2) Y. Ozawa and K. Mori: Trans. Iron Steel Inst. Japan 23 (1983) 671-675.

3) Y. Sahai and G. R. St. Pierre: Advances in Transport Process in Metallurgical Systems, (Elsevier, Amsterdam, 1992) pp. 259-326.

4) M. Iguchi and T. Chihara: Jpn. J. Multiphase Flow 11 (1997) 46-55.

5) O. J. Ilegbusi, M. Iguchi and W. Wahnsiedler: Mathematical and Physical Modeling of Materials Processing Operations, (Chapman Hall/ CRC, Boca Raton, 1999) pp. 407-413.

6) I. Leibson, E. G. Holcomb, A. G. Cacoso and J. J. Jamic: AIChE J. 2 (1956) 296-306.

7) L. Daividson and E. H. Amick, Jr.: AIChE J. 2 (1956) 337.

8) A. Hiratsuka, S. Ooishi, R. Tsujino, M. Hashimoto, K. Ohmi and M. Iguchi: Mater. Trans. 49 (2008) 2618-2624. 